\title{
Detection and identification of group B streptococci by use of pigment production
}

\author{
MICHAEL A NOBLE, JACQUELINE M BENT, ANN B WEST \\ From the Department of Microbiology, Victoria General Hospital, Halifax, Nova Scotia, Canada
}

SUMMARY Pigment production by group B streptococci (GBS) is a useful test for identification of the organisms. The test is positive in $99.5 \%$ of beta-haemolytic strains. No false-positives are noted. Non-haemolytic strains do not produce pigment. Islam's media less agar can be used as a one-step broth detector of GBS in mixed cultures. This may have application for the detection of GBS in women in labour.

When used as an identification system for GBS, serum-starch broth can be further modified by reduction of serum and starch concentrations by at least $80 \%$.

Streptococcus agalactiae (group B streptoccoci) can be significant pathogens in both children and adults. While most experienced technologists can presumptively identify them by their typical morphology and narrow band of beta-haemolysis on blood agar plates, it is important to confirm their identity by either serogrouping, or by demonstration of one of their unique physiological characteristics. Three such characterisitics are noted: hippurate hydrolysis, synergistic haemolysis (the CAMP test), and pigment production.

Hippurate hydrolysis can also be positive with beta-haemolytic streptoccoci groups $\mathrm{C}$ and $\mathrm{L}$. The CAMP test which demonstrates the synergistic haemolysis between staphylococcal B-toxin and streptococcal CAMP factor on sheep or ox red blood cells is only positive in about $84 \%$ of strains. ${ }^{1}$

Pigment production by group B streptoccoci (GBS), which is orange in colour and has characteristics of a carotenoid, ${ }^{2}$ was first noted by Lancefield in 1934 in nine of 29 strains grown anaerobically. ${ }^{3}$ Modifications of media by Fallon, ${ }^{4}$ Merritt, ${ }^{5}$ and Islam $^{6}$ have improved the sensitivity to about $97 \%$.

We describe further investigations into this test and modifications to the media described by Islam, and a useful application of one of the modifications.

\section{Material and methods}

In the first phase, tests of sensitivity and specificity of the media were done by performing Lancefield

Accepted for publication 4 November 1982 serogrouping using the autoclave method and serum produced by Wellcome Reagents, along with CAMP test and pigment production. Organisms tested included 993 streptococci, including 704 GBS and 289 beta-haemolytic streptococci (not group B) from clinical specimens. Media initially used for this was that as described by Islam, ${ }^{5}$ but was poured into $13 \mathrm{~mm} \times 100 \mathrm{~mm}$ tubes, stabbed to the depths and incubated in a Temp-Block module heater at $37^{\circ} \mathrm{C}$.

The CAMP test was performed using sheep blood agar plates produced by BBL and a strain of Staphylococcus aureus known to produce B-toxin. All tests were read and compared to a known group A (negative) and group B (positive) control.

In the second phase, modifications to simplify the media were examined. The original formulation described by Islam required $50 \mathrm{ml}$ of sterile inactivated horse serum, 5.0 g of starch and $10.0 \mathrm{~g}$ agar per litre of broth. The buffer system includes sodium dihydrogen phosphate dihydrate $\left(\mathrm{NaH}_{2} \mathrm{PO}_{4}\right)$ disodium hydrogen phosphate $\left(\mathrm{Na}_{2} \mathrm{HPO}_{4}\right)$. Nine mod- O ifications were investigated: $(a)$ reduction of serum to $10 \mathrm{ml} / 1 ;(b)$ removal of serum; (c) reduction of $\sigma$ starch to $1.0 \mathrm{~g} / \mathrm{l} ;(d)$ removal of starch; $(e)$ elimina- N tion of $\mathrm{Na}_{2} \mathrm{HPO}_{4}$ alone; $(f)$ elimination of $\mathrm{Na}_{2} \mathrm{HPO}_{4} \underset{\mathrm{N}}{\mathrm{N}}$ alone; $(g)$ elimination of both $\mathrm{NaH}_{2} \mathrm{PO}_{4}$ and $\mathrm{O}$ $\mathrm{Na}_{2} \mathrm{HPO}_{4} ;(h)$ elimination of agar; and (i) replacement of heat-inactivated horse serum with noninactivated sterile horse serum. At least 12 strains $\stackrel{\mathbb{Q}}{\rightarrow}$ including typical pigment producers and weak producers were examined with each variation.

In the third phase, after confirmation of lack of similar pigment production in 80 strains of nonstreptococci, including Staphylococcus, Enterobac350 
Production of pigment in serum starch broth media by different serogroups of beta-haemolytic streptococci.

\begin{tabular}{|c|c|c|c|c|c|c|c|c|c|}
\hline & \multicolumn{8}{|c|}{ Serogroup } & \multirow[t]{2}{*}{ Non-grouped $\dagger$} \\
\hline & $B^{*}$ & $\boldsymbol{A}$ & $C$ & $D$ & $E$ & $F$ & $G$ & $\boldsymbol{R}$ & \\
\hline $\begin{array}{l}\text { Strains } \\
\text { Pigment production } \\
\text { No pigment production }\end{array}$ & $\begin{array}{r}704 \\
689 \\
15\end{array}$ & $\begin{array}{r}68 \\
0 \\
68\end{array}$ & $\begin{array}{r}27 \\
0 \\
27\end{array}$ & $\begin{array}{r}92 \\
0 \\
92\end{array}$ & $\begin{array}{l}1 \\
0 \\
1\end{array}$ & $\begin{array}{r}38 \\
0 \\
38\end{array}$ & $\begin{array}{r}41 \\
0 \\
41\end{array}$ & $\begin{array}{l}1 \\
0 \\
1\end{array}$ & $\begin{array}{r}22 \\
0 \\
22\end{array}$ \\
\hline
\end{tabular}

*Includes 11 non-haemolytic strains of GBS

†Non-grouped with A,B,C,D,G,F,H,K,L,M,Q,R, antisera.

and Clostridium, direct inoculation of routine vaginal swabs in serum-starch broth was compared to inoculation on sheep blood agar, and classical Islam media in plates. In all instances, swabs were first inoculated on blood agar, and then on Islam plates and then into Islam tubes, which contained the original formula less the agar.

\section{Results}

In order to determine the sensitivity and specificity of the test, 704 fresh strains of GBS and 289 strains of beta-haemolytic streptococci (not group B) were examined in pure culture. Six hundred and eightynine strains $(97.9 \%)$ of GBS were positive, including $6 \%$ which were weak producers only (Table). Approximately $25 \%$ were interpretable at two hours and $50 \%$ were interpretable by four hours. All the positives were readable after overnight incubation. Of interest was that none of the 11 strains of non-haemolytic GBS produced pigment during $72 \mathrm{~h}$ of incubation. When these non-haemolytic organisms are excluded, the positivity rate for pigment production is $99.5 \%$ of beta-haemolytic GBS. This compared to $90.6 \%$ of those strains tested in tandem for CAMP test positivity. No non-GBS strains were positive for pigment production or CAMP test.

Variations of the media described by Islam demonstrated that serum and starch could be reduced by at least $80 \%$ to concentrations of $10 \mathrm{ml} / 1$ and $1 \mathrm{~g} / 1$ respectively and still produce equally visible pigment. Alterations in the buffer system, by elimination of the disodium hydrogen phosphate was associated with complete loss of pigment production. This was also associated with a reduction of pH from 7.4 to 7.3 which confirms the finding of Fallon of the importance of media $\mathrm{pH}$ prior to inoculation in production of pigment. Of interest, when the agar was removed, resulting in a serum-starch broth, the quality of pigment production was improved, in that the pigment of the weak producers became more vivid and easier to read. The nonhaemolytic, non-pigment producers were still read as negative in this system.
The use of serum that was not heat-inactivated did not alter the pigmentation, however it was found that when serum was heated and then reheated, the quantity and quality of pigment production markedly diminished.

The ease of direct inoculation into broth suggested a useful screen for some specimens, in particular vaginal swabs from women in labour. Because of lack of access to this specimen type, 119 vaginal swabs sent to the laboratory for other reasons were examined. Eleven $(\mathbf{9 . 2 \%})$ were found to be positive by routine plate method; nine $(8.2 \%)$ by the tube method. The two discrepancies could be accounted for by the very low inoculum (only one colony on the routine plate) and the fact that routine plating was always completed first. The broths were not subcultured, so that organisms may have been present but not visible.

\section{Discussion}

This study confirms that pigment production is both specific and sensitive (99.5\% for beta-haemolytic strains) of GBS. The removal of the agar is a useful alteration in the media in that it allows the pigment to concentrate and become easier to read, at an earlier time.

The correlation between non-haemolysis and non-pigment production is of interest. The nonhaemolytic strains were all urinary or vaginal isolates from different individuals well separated by time and geography, thus making it unlikely they were from a common source. As with Durand and Giraud, ${ }^{7}$ we found with these strains that no variation in the media could encourage pigment production.

Lancefield reported in 1934 one strain of GBS which during mouse passage simultaneously lost its ability to produce pigment and haemolysin. These reports when combined might suggest that the gene loci determining haemolysin production and pigment production are closely linked. However, with at least one strain which was repetitively used for quality controlling media, the ability to produce pigment was lost while haemolysin production was 
retained. In addition, four of the $\mathbf{1 5}$ pigment negative strains found in specimens were betahaemolytic. When one considers that each prior modification of the medium has resulted in increased sensitivity, perhaps these strains are still capable of producing pigment but they require a stimulus that is still absent in the existing media.

The use of Islam's agar as a one-step medium for detection of GBS has been demonstrated. Although we were satisfied that with pure culture of GBS the original concentrations of starch and serum were much in excess of what was required, it was felt that reagents may be consumed competitively in mixed cultures, and for that reason the mixed culture media included larger amounts of the two constituents. The removal of the agar results in several distinct advantages. Swabs can be directly inoculated into tubes at the bedside, rather than being sent for plating. This saving of time, in addition to the ease of pigment visualisation could reduce the time of positivity to less than the time of labour in some cases. This may be of benefit in selecting the neonates that might receive penicillin prophylaxis within two hours of birth. ${ }^{8}$

\section{References}

' Waitkins SA. Evaluation of rapid methods of identifying group B streptococci. J Clin Pathol 1980;33:302-5.

${ }_{2}^{2}$ Merrit K, Jacobs NJ. Characterisation and incidence of pigment production by human clinical group B streptococci. J Clin Microbiol 1978;8:105-7.

${ }^{3}$ Lancefield, RC. Loss of properties of haemolysin and pigment formation without change in immunological specificity in a $\triangle$ strain of Streptococcus haemolyticus. $J$ Exp Med है 1934;59:459-69.

4 Fallon RJ. The rapid recognition of Lancefield group B haemolytic streptococci. J Clin Pathol 1974;27:902-5.

${ }^{5}$ Merrit K, Jacobs NJ. Improved medium for the detecting pigment production by group B streptococci. J Clin Microbiol 1976;4:379-80.

- Islam AKMS. Rapid recognition of group B streptococci. Lancet 1977;i:256-7. (Letter).

${ }^{7}$ Durand P, Giraud P. Les Streptocoques chromogenes. Compt Rend Acad 1923;177:1333.

${ }^{8}$ Lloyd DJ, Scott KE, Kurt A, Belgaumkar TK, Wort AJ, Krause VW. Prevention of group B beta-haemolytic streptococcal septicaemia in low-birth-weight neonates by penicillin administered within two hours of birth. Lancet 1979;i:713-5.

Requests for reprints to: Dr MA Noble, Department of Microbiology, Public Health Laboratories, 5788 University Avenue, Halifax, NS B3H IV8, Canada. 